\title{
MÉXICO: LOS SIGNIFICADOS DE LA VICTORIA DE MORENA
}

\author{
MEXICO: THE MEANINGS OF THE \\ VICTORY OF MORENA
}

Henio Millán Valenzuela

El Colegio Mexiquense, A.C.

hmillan@cma.edu.mx

\begin{abstract}
The victory of Morena in the 2018 federal elections is a historical twist. The object of this article is to analyze the meanings of this victory. A mathematical model is used to find out the message of the ballot boxes and to examine the chances of being an authoritarian or democratic government. The main finding is that only in the case of Morena, the electoral result can be credited to the candidate, suggesting a strong personal leadership, which fits very well with the authoritarian solution to an old dilemma of Mexican politics between democracy and governance.
\end{abstract}

Keywords: Mexico, electoral victory, Morena, political parties and elites, authoritarianism.

\section{Resumen}

El triunfo de Morena en México en las elecciones de 2018 es un giro histórico. El objetivo de este trabajo es analizar los significados de la victoria en ese proceso. Se usa un modelo matemático para averiguar el mensaje de las urnas y para examinar las posibilidades de un gobierno autoritario o democrático. El principal hallazgo es que en sólo en el caso de Morena el resultado electoral puede atribuirse al candidato, lo que insinúa un carácter caudillista del nuevo gobierno, que encaja muy bien con la solución autoritaria al viejo dilema entre democracia y gobernabilidad de la política mexicana.

Palabras clave: México, victoria electoral, Morena, partidos y élites políticas, autoritarismo. 


\section{Introducción}

El 1 de julio de 2018, la coalición Juntos Haremos Historia (JHH), encabezada por el partido político Movimiento de Regeneración Nacional (Morena), se alzó con una victoria contundente; de esas que no se veían desde que el Partido Revolucionario Institucional (PRI) era el amo y señor del panorama electoral mexicano. Su candidato presidencial no sólo obtuvo una votación de $53 \%$ y ganó en 31 de los 32 estados de la república, sino que también obtuvo la mayoría absoluta en las dos cámaras del Legislativo federal. Por si fuera poco, se llevó los congresos locales donde hubo elecciones y cinco de las nueve gubernaturas en juego, según el Instituto Nacional Electoral (INE, 2018a):

\section{Tabla 1}

Resultados electorales 2018: congresos locales y gubernaturas

\begin{tabular}{|c|c|c|c|c|c|c|}
\hline Entidad & Congreso & Gobernador & $\begin{array}{l}\text { Morena/ } \\
\text { PT/PES }\end{array}$ & $P A N / P R D / M C$ & $\begin{array}{c}\text { PRI/Verde/ } \\
\text { PAS }\end{array}$ & Total \\
\hline Aguascalientes & Frente & PAN & 4 & 14 & & 18 \\
\hline Baja California*/** & Frente & PAN & 4 & 15 & 6 & 25 \\
\hline Baja California Sur & Morena & PAN & 15 & 1 & & 16 \\
\hline Campeche & Sin mayoría & PRI & 9 & 3 & 9 & 21 \\
\hline Coahuila*/** & Sin mayoría & PRI & 2 & 10 & 10 & 25 \\
\hline Colima & Morena & PRI & 15 & 1 & & 16 \\
\hline Chiapas & Morena & Morena & 13 & 0 & 11 & 24 \\
\hline Chihuahua & Frente & PAN & 10 & 11 & 1 & 22 \\
\hline Ciudad de México & Morena & Morena & 31 & 2 & & 33 \\
\hline Durango & Morena & PAN & 11 & 3 & 1 & 15 \\
\hline Guanajuato & Frente & PAN & 1 & 21 & & 22 \\
\hline Guerrero & Morena & PRI & 18 & 4 & 6 & 28 \\
\hline Hidalgo & Morena & PRI & 17 & & 1 & 18 \\
\hline Jalisco $* / * *$ & $M C$ & $M C$ & & 21 & 17 & 41 \\
\hline México & Morena & PRI & 42 & 2 & 1 & 45 \\
\hline Michoacán & Morena & PRD & 15 & 9 & & 24 \\
\hline Morelos & Morena & Morena & 12 & & & 12 \\
\hline Nayarit */** & Frente & Frente & 5 & 16 & 8 & 30 \\
\hline Nuevo León & Frente & Independiente & 11 & 13 & 2 & 26 \\
\hline Oaxaca & Morena & PRI & 15 & 9 & & 24 \\
\hline Puebla & Morena & Frente & 16 & 9 & 1 & 26 \\
\hline Querétaro & Frente & PAN & 3 & 10 & 2 & 15 \\
\hline Quintana Roo */** & Frente & PAN & 2 & 13 & 17 & 36 \\
\hline San Luis Potosí & Morena & PRI & 8 & 3 & 2 & 13 \\
\hline Sinaloa & Morena & PRI & 19 & 2 & 3 & 24 \\
\hline Sonora & Morena & PRI & 20 & & 1 & 21 \\
\hline Tabasco & Morena & Morena & 21 & & & 21 \\
\hline Tamaulipas*/** & Frente & PAN & 1 & 21 & 13 & 36 \\
\hline Tlaxcala & Morena & PRI & 15 & & & 15 \\
\hline Veracruz & Morena & Morena & 9 & 21 & & 30 \\
\hline Yucatán & PRI & PAN & 1 & 5 & 9 & 15 \\
\hline Zacatecas & Morena & PRI & 8 & 4 & 6 & 18 \\
\hline
\end{tabular}

* Incluye diputados de representación proporcional

**/ No hubo elección en 2018 para renovar el Congreso local 
La magnitud de la victoria ha permitido a Morena emprender modificaciones al marco jurídico legal, con la simple mayoría de legisladores; o al constitucional, con 17 de los 32 congresos locales y una mayoría calificada de diputados y senadores, que no le ha costado mucho trabajo conseguir: en el primer caso, debido a la fidelidad de sus aliados y a la ampliación poselectoral de su fracción parlamentaria; y, en el segundo, mediante la ruptura del bloque opositor que, eventualmente, podría evitar las modificaciones constitucionales.

En el otro extremo, se perfiló un serio debilitamiento de los partidos: el oficial ganó solamente un distrito y una fórmula senatorial por mayoría. El nivel de votación que obtuvo la coalición que postulaba a su abanderado presidencial ha sido el más bajo en toda la historia electoral de México (16\%) y el desprestigio profundo y generalizado parece irreversible: las imágenes y escándalos de corrupción han mellado su credibilidad hasta ubicarlo como la quintaesencia de este tipo de comportamiento. Aunque ya arrastraba problemas que ponían en entredicho su carácter hegemónico, al perder la Presidencia de la República el PRI se quedó sin su jefe nato; pero, a diferencia de la primera alternancia del año 2000, no se vislumbra entre los gobernadores la tendencia a la configuración de una unidad opositora priísta. Tampoco cuenta con suficientes representantes en el Legislativo federal para negociar las políticas públicas que deben pasar por esta instancia.

La coalición México al Frente (MF) estuvo conformada por el Partido Acción Nacional (PAN), el de la Revolución Democrática (PRD) y Movimiento Ciudadano. Unió en una sola plataforma a dos corrientes tradicionales: una de derecha; otra de izquierda. En contra de lo que pensaban sus arquitectos, la alianza fue concebida por muchos como un artificio contra natura, articulada

1 Estos son algunos ejemplos de los cambios legales: a) extinción de dominio, b) establecimiento de la Guardia Nacional, c) prisión preventiva oficiosa para delitos electorales y de corrupción, d) ampliación de delitos por los que puede ser juzgado el presidente, e) revocación de mandato y consulta popular, etcétera. con el doble propósito de impulsar la candidatura del panista y de sobrevivir al desmoronamiento perredista, cuyo monopolio de la izquierda nacional fue arrebatado por Morena.

Esta imagen simplificada no oculta la crisis de estos partidos: la candidatura del Frente se logró a costa de una notable y -probablemente- irreparable fractura en el PAN, que marginó a corrientes y personalidades destacadas de ese partido. Y lo que es peor: al amparo de formas poco aseadas, que usualmente se le endilgaban al opositor histórico: el PRI. La derrota debilitó seriamente a quienes acompañaron el ascenso del candidato, mientras sus adversarios partidistas se encuentran sin posibilidades recuperar el poder perdido. El PRD, por su parte, corre el mismo riesgo de extinción que el PRI, en la medida en que las escasas victorias que obtuvo la coalición en la que se inscribía, difícilmente pueden atribuirse a sus candidatos, mientras que su bastión tradicional -Ciudad de México- fue conquistado por el nuevo representante de la izquierda mexicana.

La combinación de una victoria contundente de Morena, el papel protagónico que ostenta su líder (Andrés Manuel López Obrador: AMLO) y la aparente crisis de los partidos, ha sembrado la inquietud de la conformación de una nueva hegemonía, en la que Morena sustituye y asume el papel que antiguamente jugaba el PRI, y en la que se regresa a las viejas formas del presidencialismo autoritario.

Contra esta tendencia, se opone la conformación de un núcleo cívico -lo que se ha llamado círculo rojo- de inclinaciones proto-democráticas, ${ }^{2}$ que sirvió al triunfo de López Obrador y que toleró sus desplantes autoritarios, en aras de desmantelar los abusos de las élites políticas y económicas del país, pero que ahora ve con recelo su gobierno, en virtud de un conjunto de símbolos que evocan una regresión en los avan-

2 Por proto-democrática se entiende la proclividad de ciertos grupos a luchar dentro de los marcos de la democracia e, incluso, a defenderlos, pero a minimizar sus componentes liberales. 
ces democráticos, que tanto costaron a los mexicanos. No obstante, el mandato puede ser tan contundente que logre vencer las potenciales resistencias de este grupo. Sobre todo, si es utilizado para una legitimación que se sustente en el consenso directo del pueblo, sin los intermediarios políticos tradicionales. En un caso, el triunfo puede llevar a un avance democrático; en el otro, a un retroceso autoritario. El avance consistiría en rescatar la democracia del dominio de las élites; el retroceso, en hacer de ese rescate la restitución del viejo sistema político, señaladamente la ausencia de controles ciudadanos del poder político, concentrado en el ejecutivo.

Explorar ambas posibilidades es el objetivo de este trabajo. Se organiza en una sección metodológica y en otra de exposición y discusión de resultados. En la primera se examina el mensaje que emiten las urnas, tras los comicios de julio de 2018. Con tal propósito, se propone un modelo matemático sencillo que busca inspeccionar si los resultados de los comicios obedecen a los partidos (instituciones) o los candidatos (caudillismo). En la segunda, se presentan y discuten los resultados de ese modelo, con énfasis en tres aspectos: contundencia de la victoria, su carácter institucional o personal y la estabilidad del pacto social que parece arropar al nuevo gobierno.

\section{Metodología}

Esta investigación se inscribe en las preocupaciones que ha suscitado el arribo de los populismos de derecha y de izquierda, que representan una amenaza para la democracia no sólo porque abren espacio a outsiders dispuestos a alterar las reglas más elementales que la hacen posible, sino porque dan cuenta de la decepción que ha despertado este régimen en amplios núcleos de la población. Su propensión a revertir la corrección política que se suele asociar a la democracia incluye el fortalecimiento y exhumación de actitudes autoritarias, legitimadas por el apoyo popular. La literatura reciente ha sido pródiga al buscar estas respuestas y ellas constituyen el paradigma en el que se mueven estas líneas. Sus referentes teóricos más recientes son Urbinati (2019), Levitsky y Ziblatt (2018) y Müller (2017).

El punto de partida para desentrañar los significados de la victoria de Morena es tratar de entender el mensaje de las urnas. Los comicios arrojaron cifras apabullantes e incontestables que recuerdan en una buena parte las que solían avalar la hegemonía del PRI. Sin embargo, en 2018 reflejaron una verdadera simpatía y entrega al candidato triunfador; y no, como sucedía antes, el éxito de una maquinaria orientada a ganar de cualquier manera; incluso, con el fraude, si no quedaba de otra.

Pero también el triunfo de Morena marca una diferencia importante con la forma en que llegaron al poder los partidos de la alternancia, a partir del año 2000: el carácter dividido de los gobiernos. Para muchos, fue el signo de los nuevos vientos democráticos, en virtud de que la predominancia consuetudinaria del PRI se caracterizaba no sólo por ocupar invariablemente el poder Ejecutivo, sino también por registrar una mayoría indiscutible en el Legislativo. De esta forma, el presidente de la república podía modificar el marco legal y constitucional, sin contrapesos significativos. Esto cambió cuando fue derrotado, primero en la Cámara de Diputados en 1997 y, tres años después, en la propia presidencia. Ahora, con la victoria de Morena parece regresar.

De ser cierto, se imponen varias preguntas que este esquema metodológico se propone abordar. En primer lugar, el carácter contundente de la victoria. Decir que Andrés Manuel López Obrador consiguió 53\% de los votos es decir mucho, pero no lo suficiente en el contexto mexicano. Tal cifra acepta una lectura plausible: el carácter plebiscitario de la elección en torno a los gobiernos panistas y priístas de la llamada alternancia democrática. En este sentido, un porcentaje tan contundente de un opositor tradicional podría significar el repudio a la forma en que aquéllos ejercieron el poder, pero no necesariamente el permiso para poner en marcha un conjunto de transforma- 
ciones avaladas por la izquierda mexicana. Para ello era preciso el predominio en las cámaras que conforman el Legislativo. En este sentido, la primera fase metodológica consiste en determinar si se logró ese permiso. La técnica utilizada es la revisión de la composición original y actual de ambos cuerpos. Los datos provienen del Instituto Nacional Electoral (INE, 2020).

En segundo término, es necesario analizar el carácter personal o institucional de la victoria. La razón es que el triunfo pudo haber significado solamente el repudio a los partidos de la transición y la aceptación de un nuevo jugador (Morena); o, alternativamente, la decepción y el rechazo a todo el sistema de partidos, fundamento de cualquier mecánica democrática. El método para averiguarlo consiste en determinar si la victoria y las derrotas obedecieron más al candidato o a su partido. La técnica utilizada es un modelo matemático sencillo que trata de determinar las contribuciones de los candidatos presidenciales y de los partidos a los resultados en el Legislativo.

El modelo es el siguiente:

Llamemos $\mathrm{D}_{1}$ a la diferencia que hay entre los porcentajes de votación obtenidos en la elección presidencial y la de senadores o diputados federales:

$$
D_{1 i}=P_{c i}-S_{c i}
$$

$P_{c i}$ es el porcentaje de votación obtenida por el candidato presidencial de i-ésima coalición y $S_{c i}$ el de sus candidatos a senadores o a diputados. Es claro que esta expresión indica la contribución tanto del candidato presidencial como la de los legisladores que contendieron de forma no coaligada. Es decir, excluye la de los candidatos de la coalición.

Propongamos otra diferencia:

$$
D_{2 i}=S_{c y A i}-S_{c i}
$$

$S_{c y A i}$ es el porcentaje de votación que obtuvieron los candidatos a senador o a diputado de la coalición i-ésima y sus aliados que compitieron de forma independiente.
La diferencia $D_{2 i}$ muestra la contribución al partido de origen de los aliados-no coaligados ( $A$ ); no a la coalición, aunque aquél haya formado una alianza con otras fuerzas políticas para elecciones a otros cargos y/o en otras entidades.

Así, la aportación personal de un candidato presidencial a su votación es:

$$
D_{1 i}-D_{2 i}=P_{c i}-S_{c i}-\left(S_{c y A i}-S_{c i}\right)=P_{c i}-S_{c y A i}
$$

La combinación de los tres indicadores informa sobre el mensaje de los comicios:

i. $D_{1 i}-D_{2 i}>0$ : la figura del candidato presidencial aumenta, por sí sola, la votación presidencial; si $D_{1 i}-D_{2 i}<0$, la disminuye.

ii. $D_{2 i}>0$ : los $(A)$ aumentan la votación del partido; no de la coalición. Por construcción, siempre es positiva. Su magnitud muestra cuánta es su aportación. Si es alta, el partido de origen depende crucialmente de ellos; si es baja, son ellos los que dependen del partido.

iii. $D_{1 i}$ exhibe si los A contribuyeron a acentuar o contrarrestar el impacto de la figura del candidato presidencial sobre la votación del Ejecutivo federal. Si $D_{1 i}>$ $O$ se combina con $D_{1 i}-D_{2 i}>0$, abonan a la votación; si lo hace con $D_{1 i}-D_{2 i}<0$, la contrarrestan. Si $D_{1 i}<O$ y $D_{1 i}-D_{2 i}>0$, restan votación a la imagen positiva del candidato presidencial; si $D_{1 i}<O$ y $D_{1 i}-D_{2 i}<0$, amortigua la caída en la votación provocada por la candidatura presidencial.

\section{Resultados y discusión}

\section{La victoria de Morena, contundente}

Con relación al primer aspecto, la tabla 2 y la figura 1, elaborados con datos de INE (2018), reflejan los resultados en torno a la contundencia de la victoria electoral de Morena: 
Tabla 2

Elección 2018: diputados, senadores y porcentaje de votación

\begin{tabular}{|c|c|c|c|c|c|c|}
\hline \multirow[t]{3}{*}{ Partidos políticos } & \multirow{2}{*}{\multicolumn{2}{|c|}{$\begin{array}{c}\text { Fórmulas senatoriales } \\
\text { Entidades }\end{array}$}} & \multirow{3}{*}{$\begin{array}{c}\text { Distritos } \\
\text { Diputados de } \\
\text { Mayoría }\end{array}$} & \multicolumn{3}{|c|}{ Participación en la votación a: } \\
\hline & & & & Presidente & Senadores & Diputados \\
\hline & Mayoría relativa* & Primera minoría** & & $\%$ & $\%$ & $\%$ \\
\hline PAN & & 1 & 5 & & 1.07 & 1.25 \\
\hline MOVIMIENTO CIUDADANO & 1 & 0 & 0 & & 1.01 & 0.48 \\
\hline PRD & 0 & 0 & 0 & & 0.17 & $0.22 \%$ \\
\hline COALICIÓN MEXICO AL FRENTE & 5 & 15 & 63 & 22.8 & 25.29 & 25.7 \\
\hline PRI & 0 & 0 & 1 & & 6.86 & 7.78 \\
\hline ALIANZA SOCIAL & 0 & 0 & 0 & & 1.06 & 1.26 \\
\hline VERDE & 0 & 0 & 0 & & 2.13 & 2.55 \\
\hline COALICIÓN TODOS POR MEXICO & 1 & 11 & 13 & 16.41 & 12.71 & 12.26 \\
\hline MORENA & 1 & & 8 & & 1.18 & 1.26 \\
\hline PT & 0 & 0 & 0 & & 0.09 & 0.12 \\
\hline ENCUENTRO SOCIAL & 0 & 0 & 0 & & $0.05 \%$ & 0.1 \\
\hline COALICIÓN JUNTOS HAREMOS HISTORIA & 24 & 5 & 210 & 53.19 & 42.24 & 42.01 \\
\hline Candidatos independientes & 0 & 0 & 0 & & 1.97 & 0.96 \\
\hline TOTAL & 32 & 32 & 300 & & 95.781 & 95.732 \\
\hline
\end{tabular}

Fuente: elaboración propia, con datos del INE (2018b).

Figura 1

\section{Votación: coaliciones y sus aliados no coligados}

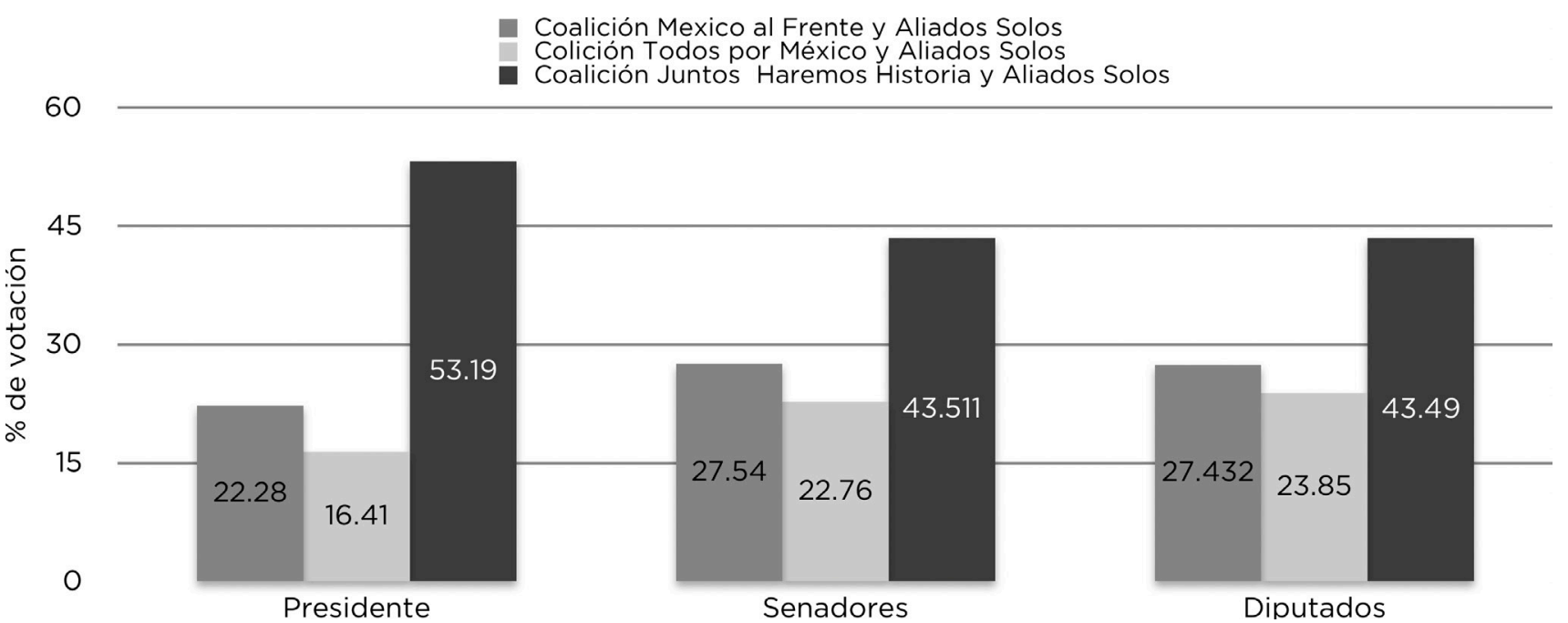

Fuente: elaboración propia, con datos de la tabla 1.

Es fácil notar que AMLO alcanza la mayoría absoluta de la votación. Ni aun sumándolas, las coaliciones opositoras podrían ensombrecer ese triunfo. Tal hecho no es exclusivo de la votación presidencial: también sucede con las de senadores y diputados. La lectura es que la ciudadanía no escatimó su entrega a la coalición ganadora, a fin de que pudiera emprender los cambios legales que considerase necesarios para materializar sus promesas de campañas. No es un despropósito afirmar que el respaldo del votante fue a favor de casi cualquier modificación que pretendiera impulsar López Obrador.

La composición original del Legislativo fue una mayoría ampliada en ambas cámaras. En primer lugar, la legislación vigente permite ocho por ciento de sobrerrepresentación al partido que haya obtenido la ma- 
yoría en el recinto de los diputados. En segundo término, varios partidos de la coalición Juntos Haremos Historia cedieron diputados a Morena para que lograra la mayoría simple (251), pero junto con sus aliados y otros que integraron una coalición distinta ha logrado la mayoría calificada, necesaria para hacer cambios constitucionales. En el caso del Senado, ésta no se ha concretado, pero sí la mayoría simple.

Tabla 3

Composición actual de las cámaras de diputados y senadores

\begin{tabular}{|c|c|c|c|c|}
\hline Partidos políticos & Diputados & Senadores & Diputados & Senadores \\
\hline & \multicolumn{2}{|c|}{ Número absoluto } & \multicolumn{2}{|c|}{$\%$} \\
\hline Morena y sus aliados & 399 & 71 & 84.6 & 55.46875 \\
\hline Morena & 252 & 61 & 50.4 & 47.65625 \\
\hline Partido del Trabajo & 46 & 6 & 9.2 & 4.6875 \\
\hline Partido Encuentro Social & 24 & 4 & 4.8 & 3.125 \\
\hline Partido Verde Ecologista de México & 11 & 7 & 2.2 & 5.46875 \\
\hline Partido Acción Nacional & 77 & 25 & 15.4 & 19.53125 \\
\hline Partido Revolucionario Institucional & 48 & 13 & 9.6 & 10.15625 \\
\hline Movimiento Ciudadano & 27 & 8 & 5.4 & 6.25 \\
\hline Partido de la Revolución Democrática & 12 & 3 & 2.4 & 2.34375 \\
\hline Sin Partido & 3 & 1 & 0.6 & 0.78125 \\
\hline TOTAL & 500 & 128 & 100 & 100 \\
\hline
\end{tabular}

Fuente: elaboración propia, con datos de Cámara de Diputados (2020) y Cámara de Senadores (2020).

\section{El carácter caudillesco de la victoria}

Una vez que se ha mostrado cómo la victoria de Morena ha sido contundente y tiende a consolidar una nueva hegemonía, se aborda el segundo resultado sobre el carácter personal o institucional del triunfo. La tabla 4 recoge la matriz que combina el primer y el tercer indicadores, una vez que se estiman con los datos del INE (2018):

Tabla 4

Contribución de candidatos presidenciales a sus coaliciones electorales

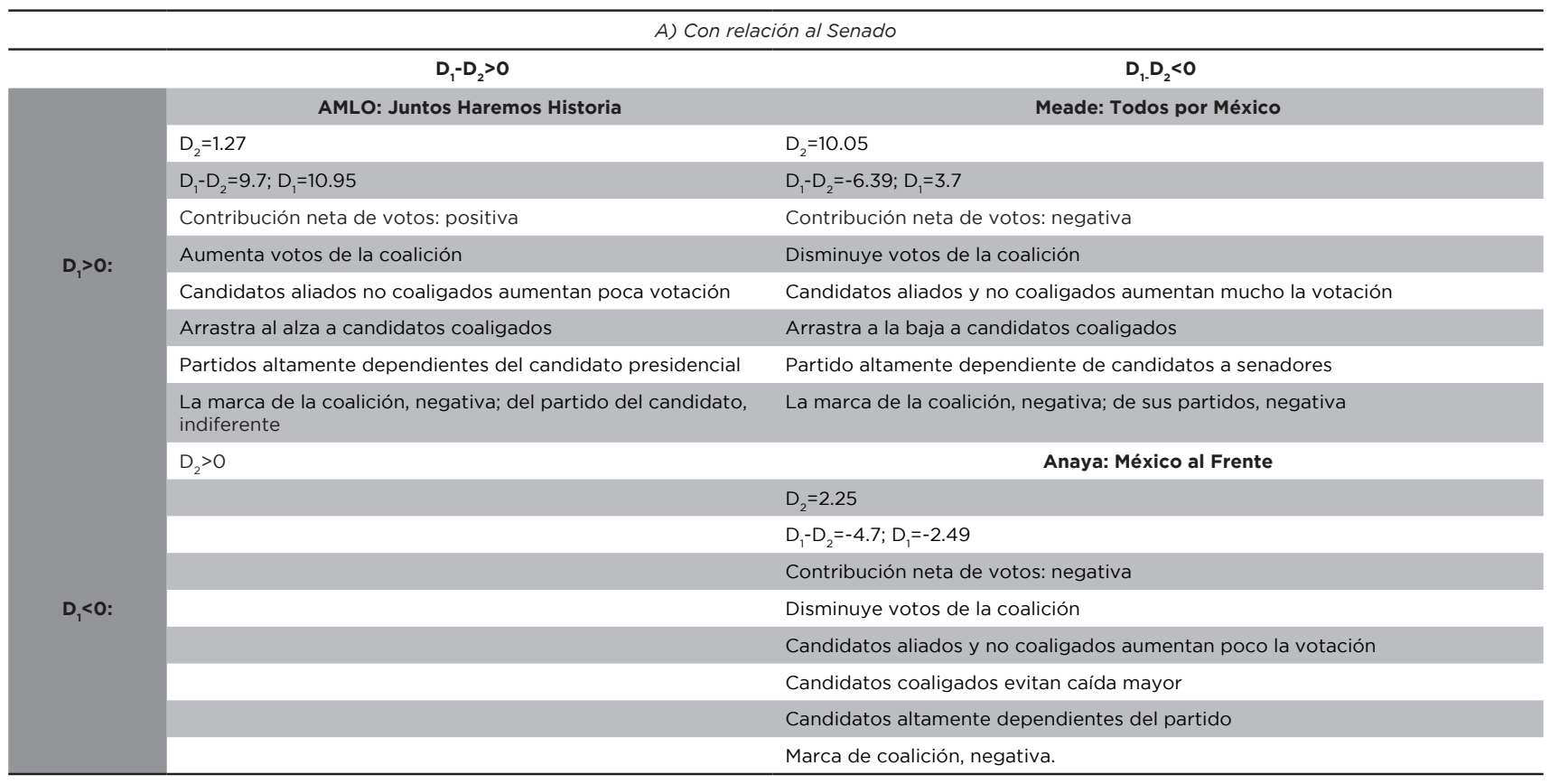


B) Con relación a los diputados de mayoría

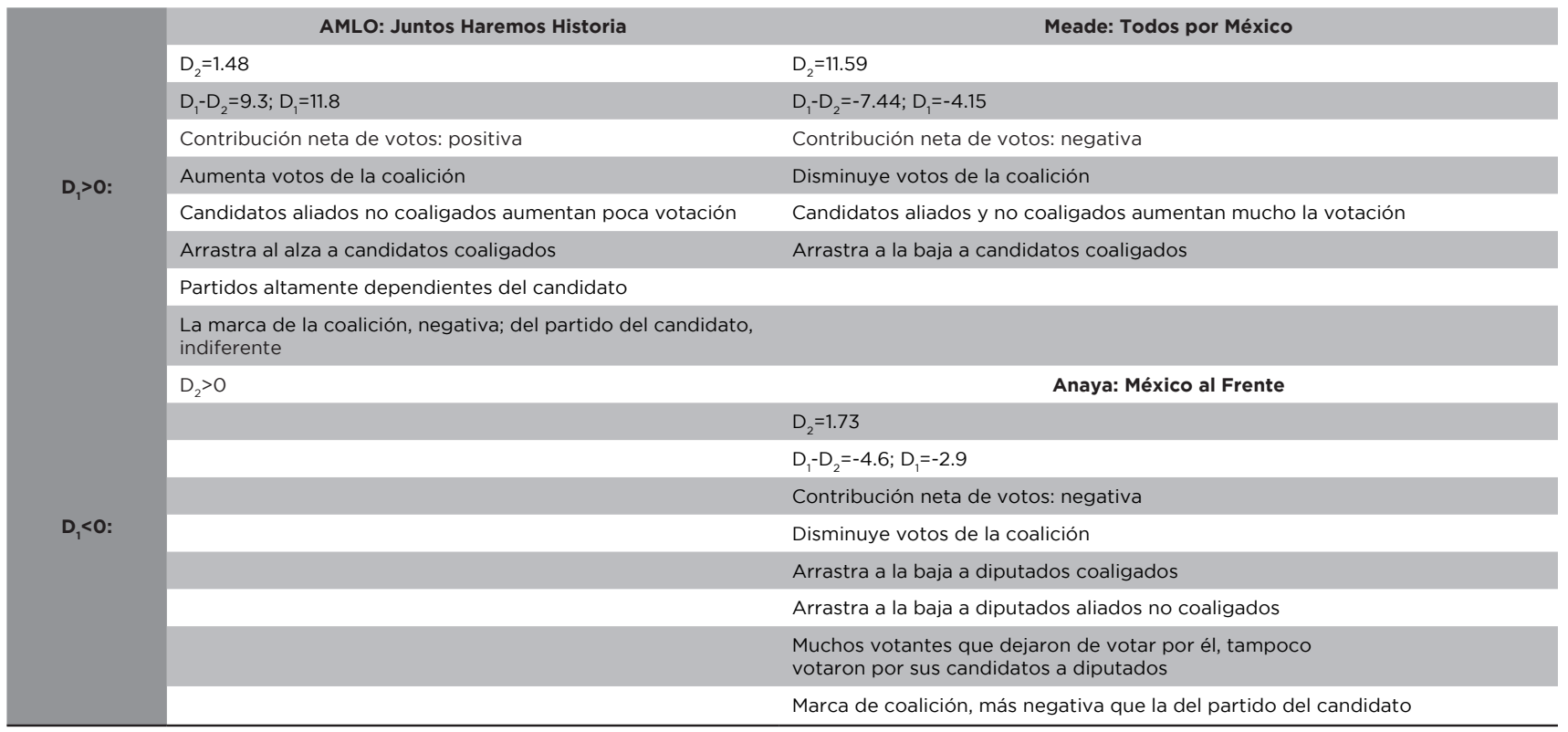

Fuente: elaboración propia con base en datos de la tabla 2 y figura 1.

Las imágenes son las siguientes:

i. AMLO es el único candidato que presenta una imagen positiva; además, su aportación personal a la votación presidencial es considerable. Tanto José Antonio Meade (Todos por México) como Ricardo Anaya (México al frente) fueron figuras negativas que debilitaron la votación potencial.

ii. En este hecho se esconde una actitud simbólica, en la medida en que estas dos personas representaron la encarnación de la clase política que emergió de la transición de la democracia y que medró de su operación deformada: injusticia, inseguridad, ineficacia y corrupción. La concepción negativa es el signo del rechazo a tales élites políticas y el llamado a su reemplazo, probablemente definitivo.

Millán (2012: 180) demostró que registraban un bajísimo grado de representatividad de los ciudadanos (2.7, en promedio, en una escala de 0 a 10). Así se revelaba la considerable distancia hacia los actores y sus conflictos sociales, los cuales debieron dirimirse al margen de la institucionalidad y, a menudo, de la legalidad. Ejemplos sobran: la constitución de autodefensas ante la incapacidad de suministrar seguridad pública; la pasividad frente a la violencia contra propiedades públicas y privadas que aprendieron a desplegar los movimientos sociales, así como la tolerancia a aceptar sus acciones paralizantes, aun cuando se vulneraba el derecho de un grupo más amplio de personas; la multitud de casos sin resolver y, por ello, sin castigo, que involucraron a miles de muertos y de desaparecidos.

iii. La cifra de votación de AMLO (53\%) revela precisamente la alianza contra esa clase política de actores con proyectos en disputa. Según Millán (2012: 195), el componente antimoderno de la sociedad mexicana es $31.5 \%$. En general, se identifica con el lado antiliberal y bucólico de la ambigua propuesta económica y social que el candidato triunfador esgrimió durante 18 años de campaña; pero no alcanza a brindar la porción mayoritaria que obtuvo en los comicios de julio. Fue pre- 
ciso que se sumara un contingente considerable de actores modernos. Se trata del quiebre del bloque hegemónico que, treinta y tantos años atrás, condujo al triunfo del neoliberalismo. Pero también de la alternancia.

iv. Por lo pronto, lo que interesa es el primer mensaje. La eliminación de la élite política que medró de la democracia emergente permite que el proyecto de nación se vuelva a dirimir entre los actores modernos y sus rivales pre y posmodernos. Sólo en este sentido se explican los contrastes entre el candidato en campaña y el presidente en funciones: a) la necesidad de preservar los fundamentales de la economía (finanzas públicas equilibradas; no endeudamiento; no impuestos adicionales; autonomía del banco central; tipo de cambio flexible, etcétera) y el compromiso con el libre comercio; b) las reformas estructurales, especialmente en el ámbito energético, han sido abandonadas, sin que se haya cambiado su marco normativo; c) la cancelación de la construcción del nuevo aeropuerto como símbolo de la descolonización del Estado y la recuperación de la primacía de la política sobre la economía; y d) el desplazamiento de la tecnocracia de los órganos autónomos y de las esferas de decisión.

Estos son algunos ejemplos de que el triunfo de AMLO representa el barrido de la élite política tradicional, a fin de que el Estado vuelva a ser el escenario en el que se enfrentan, pero también se equilibran, los intereses en pugna.

v. Aunque la contribución de (A) es invariablemente positiva, su magnitud es elocuente: la más baja se registra en el caso de la coalición JHH, que llevó a AMLO a la victoria. En el otro extremo, se encuentra el aglutinamiento Todos por México (TM), liderado por el PRI, postulante de Meade.

El mensaje alude a la relación entre el partido y sus líderes más conspicuos. En el primer caso y, especialmente en el de Morena, una cuota tan baja indica que am- bas asociaciones son irrelevantes como dispositivos electorales y que los ( $A$ ) son altamente dependientes de un partido sin poder propio y, por esta vía, del que le suministra el carisma de AMLO. Se trata de un esquema muy proclive al tipo ideal de dominación, cuya legitimidad es: "De carácter carismático: que descansa en la entrega extracotidiana a la santidad, heroísmo o ejemplaridad de una persona y a las ordenaciones por ella creadas o reveladas (llamada) (autoridad carismática)" (Weber, 1922/2002:173).

En la Biblia, santo significa apartado. Es decir, separado del mundo y su proclividad al pecado (Diccionario Bíblico, 2018). Y el de la democracia mexicana es la corrupción de los políticos. Por tal razón, el carisma de AMLO es, fundamentalmente, un halo de honestidad y de la lucha contra la corrupción.

Por tal razón, el candidato ha vendido la idea increíble de que es suficiente su ejemplo personal para que los gestores públicos y privados destierren la práctica de la corrupción.

Lo sorprendente no es que la haya propagado, sino que la ciudadanía la haya comprado: el carisma es un atributo personal que legitima precisamente porque es capaz de proyectar sus beneficios hacia el conjunto de la comunidad. Por eso se hace creíble lo que cualquier persona sabe que es una fantasía bien intencionada.

El corolario es nítido: el cambio que anuncia la Cuarta Transformación es, ante todo, la renovación moral de la política que, en principio, debió haber traído consigo el arribo de la democracia: poder del pueblo y una gestión pública que responde honestamente a sus intereses. Pero este renacimiento sólo puede llevarse a cabo por un santo, el apartado del mundo político: López Obrador.

A diferencia del de Obregón, este caudillismo goza de un halo de santidad que es reconocido por la ciudadanía y no como sucedía con el sonorense- únicamente por la clase política triunfadora. 
vi. El caso de la alianza TM, que abanderó Meade, exhibió la situación contraria. La alta cifra que registra la contribución de los (A), tanto los que contendieron por una senaduría o una diputación federal $\left(D_{2 i}=10.5\right.$ y $D_{2 i}=11.59$, respectivamente) revela los dos lados de una misma moneda: en primer lugar, el deterioro profundo de los partidos que la conformaron, especial y notablemente del PRI, pero también del mercantilismo político-electoral de sus coaligados: el Verde y Alianza Social, símbolos de la degeneración en la que desembocó la transición democrática. Por el otro, muestran la alta dependencia de las personalidades que esos institutos encararán, si emprenden la reconstrucción. Ambos datos exhiben un giro histórico, en virtud de que la situación solía ser al revés: era el partido el que suministraba la posibilidad de triunfo a candidatos que, a menudo y para todo efecto práctico, eran anónimos para la ciudadanía.

La consecuencia inmediata de este mensaje es el encarecimiento del apoyo de esas personalidades. Éste puede usarse para trasladarlo a Morena y a su líder indiscutible, como de hecho ha sucedido. En la medida en que este partido es irrelevante por sí mismo y este último acusa notables síntomas de caudillismo carismático, las novedades abonan a la crisis del sistema de partidos, que ha iniciado con el desplazamiento de las élites políticas tradicionales.

vii. La situación de MF es un caso intermedio: la imagen del candidato presidencial aparece como principal (aunque no la única) responsable de la derrota. La aportación de los A evitó que la caída fuera más grande; sin embargo, es muy pequeña $\left(D_{2 i}=2.25\right.$ y $\left.D_{2 i}=1.73\right)$. Muestra la escasa autonomía de la marca que registraron las personalidades, especialmente la del PAN. Las dos cifras emiten un claro mensaje: a) la que, en la tradición de este instituto, se anida en la posibilidad de reconstruir una verdadera oposición y, por ello, un sistema más estrecho de partidos (¿bipartidismo?); y b) las dificultades para conformar los lideratos necesarios para esta tarea, de frente a la enorme fractura que cimentó el ascenso de Anaya y su grupo. Esta última señal puede ser el factor decisivo para que la semilla de la primera parte del recado fructifique. La combinación de ambas cifras anuncia que la segunda es una crisis coyuntural, que puede convertirse en otra de naturaleza estructural.

En resumen, las urnas emiten un mensaje claro: la cuarta transformación a la que aspira AMLO es, en esencia, la intención de renovar moralmente la sociedad, especialmente la gestión pública de la sociedad, en dos sentidos: contra la corrupción y en favor del control ciudadano de sus representantes, tanto electos y delegados. Es, en este sentido, el deseo de reencarrilar la democracia, que desembocó en un régimen deformado y elitista. Aunque tiene antecedentes más remotos, el arribo a la democracia ocurrido en el año 2000 fue el inicio -y sólo el iniciode la cuarta trasformación.

En segundo lugar, la renovación moral sólo puede ser emprendida por un líder carismático -en el sentido weberiano-, al que se le endilga un halo de santidad en el lenguaje bíblico. La razón es que es el único que ha mostrado -en el imaginario popularsituarse al margen de la clase política que medró de la transición y de las instituciones ciudadanas, capturadas por los partidos y por esa propia élite.

En tercero, esta encomienda acarrea un triple proceso que seguramente acompañará a la cuarta transformación: la crisis del sistema de partidos, la renovación de la clase política y el surgimiento de un caudillismo, con vigorosos poderes arbitrales.

\section{Hacia un nuevo pacto social: ¿estable o inestable?}

La alianza entre empresarios y estratos medios condujo a la conformación de un bloque hegemónico, que se encargó de minar 
las bases del sistema político mexicano tradicional y de aupar, hasta el triunfo indiscutible, al proyecto neoliberal. Hoy, éste se encuentra en crisis y tal bloque se ha desmoronado. En eso consiste, en esencia, la victoria de AMLO. ¿Cómo sucedieron estos fenómenos y cómo se conformó una nueva alianza hegemónica? ¿Es ésta el prolegómeno de un nuevo pacto social? De ser así: ¿promete ser estable y, por tanto, cimentar una nueva etapa estructural?

El proyecto neoliberal se cimentó en un pacto social que, a diferencia del cardenismo y el priísmo histórico, se caracterizó por su carácter excluyente. La misma conformación del bloque hegemónico que lo impulsó anunciaba que en él cabían actores típicamente modernos -empresarios y estratos medios-, pero no aquellos que habian constituido las bases consensuales efectivas del viejo sistema político mexicano: las clases populares; en especial, la obrera y la campesina. Aglutinadas en organizaciones corporativas, brindaban su apoyo al Estado de la Revolución a cambio de una serie de concesiones dosificadas de política pública: precios de garantía a los productores del campo, reparto agrario, salario mínimo, seguro social, fondos para la vivienda, distribución gubernamental de bienes básicos y representación en los órganos de gobierno y administración de empresas paraestatales, desde gubernaturas y curules legislativas hasta asientos en los consejos directivos.

Así se tejió el pacto cardenista, en su tarea de construir el Estado Mexicano mediante la concentración del poder en el Ejecutivo. Hizo efectivas sus facultades constitucionales y logró extenderlas hacia la esfera metaconstitucional, gracias a la alianza entre masas corporativizadas y el Estado. Así le brindaron la triple condición de ser jefe de Estado, gobierno y de partido. Prácticamente la totalidad de la sociedad mexicana fue tutelada y controlada por ese Estado (Córdova, 1973) y la Presidencia de la República ejerció capacidades arbitrales entre sus miembros, no sólo entre la élite política (Aguilar, 1982). Igual que, antes, lo había hecho Porfirio Díaz (Roeder, 1970).
El problema fue que tal pacto derivó en burocracias sindicales y liderazgos campesinos que aprendieron a extraer rentas $-y$, por tanto, privilegios- del Estado al aprovechar su papel en el control político. Para hacerlo, debían negociar beneficios a favor de sus representantes, aunque tales prebendas fueran dosificadas y ajustadas a las prioridades del desarrollo nacional, dictadas -por otra parte- por el presidente en turno. De esta forma, el viejo Estado debía incorporar necesariamente los intereses populares, aunque fuera controlados por las organizaciones corporativas subordinadas al Estado.

El ascenso del neoliberalismo trastocó este pacto, al cimentarse en un bloque hegemónico más constreñido: el de los empresarios y estratos medios. Era, por su naturaleza, de índole excluyente, pues, a diferencia del anterior, marginaba a las organizaciones campesinas y obreras. Éstas dejaron de ser relevantes para el diseño e instrumentación de las políticas públicas e, inclusive, para la actividad electoral. $Y$ con este nuevo papel se desmanteló, diluyó o desvaneció buena parte de las acciones a favor de las masas campesinas. La política social se ciudadanizó y, en ese carácter, buscó favorecer a los más desfavorecidos mediante acciones focalizadas a individuos, y no generalizadas a sectores sociales.

La exclusión de tales sectores imprimió, desde un inicio, un rasgo inestable a ese pacto. Ese ha sido uno de los elementos que ha contribuido a la crisis política del neoliberalismo; el otro fue la emergencia de los actores posmodernos.

Las otrora organizaciones populares atadas al liderazgo estatal se independizaron crecientemente del Estado. Lo mismo sucedió con otras que nacieron autónomas o se hicieron al fragor de la lucha. Con la democracia estuvieron en posición de negociar su apoyo a los partidos políticos y, a menudo, a desplegar una industria de la protesta.

La emergencia de los actores posmodernos fue determinante también para la conformación del nuevo pacto, que a la postre llevaría al triunfo del AMLO y al retorno del proyecto reformista que, en su tiempo, 
pretendió activar sin éxito Luis Echeverría Álvarez (1970-1976). Su contribución fue fundamental por dos razones: por la alianza que tejieron con las causas populares, incluidas las que abanderan las organizaciones corporativas paraestatales. Y, además, porque este tipo de actores son típicamente de clase media. De esta forma, contribuyeron a la ruptura del bloque hegemónico empresarios-clase media, en el que se fundaba el proyecto neoliberal. Éste no supo responder a las nuevas orientaciones políticas y culturales de la posmodernidad: ecología, anti-consumismo, anti-mercantilismo de las relaciones humanas, diversidad sexual e individual, etcétera. En esencia, todas ellas, contrarias a la lógica de la del capitalismo sin freno que, en el fondo, anima al proyecto neoliberal.

Pero éste tampoco pudo satisfacer a sus aliados naturales: los segmentos meritocráticos de las clases medias. El lento crecimiento económico no se tradujo en la proliferación esperada de empresas capaces de contratar en buenos términos a sus miembros. Antes bien: después de una etapa en la que se privilegió el trabajo calificado, éste declinó continuamente. Y la expansión del empleo fue acompañada de baja de salarios. La transformación del régimen de pensiones y la perspectiva de obtener un monto jubilatorio de aproximadamente $26 \%$ del salario actual inculcaron incertidumbres suficientes para marcar una distancia creciente con la política neoliberal. En el mismo sentido operó una imagen acicateada por la desigualdad social.

Todo ello reforzó la idea de que el nuevo modelo no había podido desprenderse de sus componentes premodernos y rentistas. Los regímenes neoliberales debieron conservar ciertos rasgos del antiguo pre-modernismo, en aras de evitar manifestaciones que amenazaran la gobernabilidad. Pero sobre todo, observaron que esos privilegios habían sido mayoritariamente acaparados por la corrupción de la élite política que emergió del proyecto neoliberal y, más tarde, del arribo democrático.

En este sentido, la separación de la clase media del bloque hegemónico transcurrió tanto por la emergencia de nuevos actores anidados en esa categoría (los posmodernos) como por la insatisfacción de la capa moderna de esas clases: la meritocrática.

A esta tendencia a la inclusión se suma el alineamiento empresarial. Sin haber sido incorporados en el partido oficial, los empresarios fueron corporativizados por la política de Cárdenas a través de la Ley de Cámaras, que los obligaba a organizarse y, así, convertirse en interlocutores del Estado. En tiempos más recientes fueron furibundos opositores a AMLO, especialmente durante la última campaña presidencial. Sin embargo, todo cambió después de la victoria electoral: aunque la intención de separar el poder político del económico es una vía que alimenta las tensiones y desavenencias entre el gobierno y los empresarios, muchas de sus demandas han sido atendidas, como la necesidad de respetar algunas de las reformas estructurales, así como el compromiso de conservar los fundamentales de la economía y el libre comercio. A cambio, prometen cooperar con los dos pilares distributivos de la política de AMLO: la inclusión de jóvenes como aprendices en sus empresas, la inversión en el sur-sureste y en programas concertados de inversión.

De esta forma, parece conformarse un pacto social nuevo, de naturaleza incluyente. Muy parecido al que se tejió en la época cardenista. Este carácter incluyente es una de las bases que ayuda a pronosticar cierta propensión hacia un pacto social estable, capaz de inaugurar una nueva época en la historia mexicana.

\section{El dilema entre gobernabilidad y democracia: la tentación autoritaria}

El carácter incluyente del nuevo pacto es necesario, pero no suficiente, para la estabilidad. Ha logrado desterrar muchas de las preocupaciones, pero ha instaurado otras. Específicamente, en el ámbito económico. A ellas se agregan algunas que pueden dar al traste con ese atributo del pacto: las tendencias autoritarias. 
La personalidad del candidato triunfador abona a estos temores: son muchos sus desplantes que apuntan en esta dirección. Sin embargo, son los mensajes de la elección, la polarización deliberada, la agresividad -a menudo intolerante- de sus huestes $\mathrm{y}$, sobre todo, la tendencia histórica a resolver el dilema entre gobernabilidad y democracia mediante el sacrificio de este régimen, los que mantienen activadas las alertas.

El mensaje de la elección es contundente: se suministra al vencedor un halo de santidad, que no sólo refuerza el carisma, sino que también al lado de la crisis de los partidos y el consecuente desplazamiento de la clase política tradicional, le brinda la legitimidad para ejercer una autoridad claramente caudillista. Ese halo también habilita a sus seguidores de una intolerancia, cuya agresividad ha llegado frecuentemente hasta la violencia. Cualquier crítica es vista como un intento de socavar la imagen de pureza del líder. Es decir, de su santidad. Al estilo de Durkheim (2006), se cumple el papel del tótem en las formas elementales de la vida religiosa: es la representación misma de la comunidad. En este caso, el pueblo mismo.

Esta combinación de tendencias caudillistas y huestes entregadas refuerzan un viejo rasgo estructural de la historia mexicana: el carácter arbitral del ejecutivo federal. Su ejercicio demanda una institucionalidad blanda, cuya manifestación más evidente es la distancia entre la ley y su aplicación administrada. La separación puede rastrearse con tino hasta la colonia; pero es con el triunfo de las Reforma liberal del siglo XIX y, sobre todo, con el porfiriato, donde se encuentran sus rasgos más estructurales.

Los liberales decimonónicos derrotaron a los conservadores con un programa típicamente moderno. A través de él procuraban iniciar los dos instrumentos básicos de todo proceso de modernización: la expansión del Estado y del Mercado (Aguilar, 1968). Ese fue el sentido último de las Leyes de Reforma y de la Constitución de 1857. La pequeña propiedad agraria (la vía farmer), el federalismo y el régimen democrático animaban ese doble proceso. Sin embargo, cada vez que intentaban ponerlas en práctica se enfrentaban con la reacción de actores premodernos, plasmada en revueltas frecuentes: campesinas, indígenas, militares y eclesiásticas. Estos cuerpos habían construido un orden en el ámbito rural, castrense y espiritual, tejido con elementos premodernos: los vínculos personales y jerárquicos (Escalante, 1993), que ante la aplicación administrada de la ley pugnaban por la excepcionalidad. La lucha significaba la imposibilidad de implantar la obediencia a la autoridad central: así lo exigían la gobernabilidad y la propia construcción estatal.

Su atención cabal, por otro lado, traía consigo la ingobernabilidad del otro polo: el moderno. Su capacidad para propiciar inestabilidad había quedado de manifiesto en la revolución de Ayutla de 1854 y, más tarde, en la Guerra de los Tres Años.

Ambos episodios culminan con medio siglo en el que el predominio de los cuerpos tradicionales, herederos de la mecánica coIonial, habían impedido la formación del Estado, por un lado, y del mercado porque el principal factor de producción (la tierra) se encontraba inmovilizada en la propiedad de la iglesia y de las comunidades. La rebelión triunfante de los liberales demostró que un núcleo relativamente pequeño de personas fue capaz de interesar a capas numerosas de la sociedad y de derrocar a las viejas élites de origen colonial.

El dilema mostraba su cara más evidente: sin las leyes, los actores modernos se convertían en factor de inestabilidad y, por ello, ponían en juego la gobernabilidad. Por otro lado, su aplicación a rajatabla provocaba la misma reacción, pero ahora en el frente premoderno.

La solución la adelantó Juárez, pero la instrumentó Díaz, de forma impecable: "la ley existe, pero no se cumple"; más bien: se administra; se aplica en casos extremos, señaladamente, en el caso de los insumisos irredentos.

Se configuraba así el equilibrio entre actores sociales (modernos y premodernos), que fue la base para la construcción del Estado: primero, del oligárquico-liberal; des- 
pués, del que emergió de la Revolución de 1910.

La heterogeneidad social condujo a ese equilibrio social. Pero tras éste se escondía otra faceta del dilema original: la que media entre democracia y gobernabilidad. Sin aplicación cabal de la ley, no hay imperio del derecho; y sin estado de derecho (rule of the law), no hay democracia (O'Donell, 1998). Pero aceptarla era desaprovechar la posibilidad de construir el Estado y la gobernabilidad.

Así se ha instalado en México un dilema entre gobernabilidad y democracia. A él se han tenido que enfrentar todos los regímenes desde Porfirio Díaz, desde finales del siglo XIX. Éste configuró el equilibrio mediante la subordinación o eliminación de caciques, así como en el encumbramiento de antiguos compañeros de lucha (Guerra, 1980). Los revolucionarios, con procedimientos similares, a los que se agregaron el aglutinamiento de los caudillos políticos-militares en el seno de la Familia Revolucionaria y, más tarde, la incorporación corporativa de las masas.

La consecuencia, en ambos casos, fue doble: sacrificio de la democracia, en aras de asegurar la gobernabilidad; y, segundo, atribuciones arbitrales metaconstitucionales del Ejecutivo. Sin ellas era imposible mantener los equilibrios entre los actores y operar la blandura de la institucionalidad.

Con la llegada de la democracia en 2000 , los gobiernos panistas volvieron a encarar el dilema. Sin embargo, la solución fue al revés: salvaguardar la democracia e inmolar la gobernabilidad (estaban obligados, dados los antecedentes autoritarios del viejo sistema político). El poder, hasta entonces concentrado en el Ejecutivo, se dispersó.

Pasó a manos del Legislativo y, por esta vía, de los partidos políticos; pero también -y señaladamente- de los gobernadores, quienes ahora fungían como verdaderos virreyes, sin una autoridad central que los disciplinara. Y quizás más importante: la mengua de esta capacidad disciplinaria exhumó la influencia de los poderes fácticos: sindicatos poderosos, empresarios rentistas y narcotraficantes.
La dispersión del poder ha tenido consecuencias muy importantes para el desarroIlo. Como lo han demostrado Acemoglu y Robinson (2012), éste depende crucialmente tanto de las instituciones económicas como de las políticas. Ambas, inclusivas.

El carácter incluyente de las económicas activa la innovación, la productividad y la inversión, al impedir el predominio de una élite económica que obtiene beneficios e ingresos de actividades rentistas, que normalmente provienen del trabajo ajeno. Las políticas se distinguen por la pluralidad y la concentración democrática del poder. Esta concentración es condición indispensable para activar el crecimiento económico.

Pero cuando se opera por vías autoritarias, el crecimiento es alto, pero al final está destinado a desembocar en el estancamiento económico.

La causa reside en que no existen incentivos para la innovación y el progreso técnico que, última instancia, son el motor más importante del desarrollo sostenido, como lo postulan el modelo de Solow y las teorías de crecimiento endógeno. Eso fue lo que le pasó a la Unión Soviética.

La solución autoritaria al dilema democracia-gobernabilidad posibilitó el crecimiento alto, tanto en el porfiriato (Moreno-Brid and Ros, 2009) como durante los gobiernos postrevolucionarios; pero culminó con el lento crecimiento del PIB per cápita que caracterizó el final del dominio priísta.

La dispersión del poder que resultó de la salida democrática ha continuado ese estado de estancamiento. Pero además, ha conducido a una pérdida tal de la gobernabilidad, que el país parece desmoronarse como probablemente lo hizo en otra época de profunda fragmentación del poder: la primera mitad del siglo XIX, que llevó a la pérdida de más de la mitad del territorio.

AMLO -y éste es uno de los mandatos de las urnas- debió encarar de nuevo el dilema. Ha optado, sin duda, por la vía de recuperar la gobernabilidad. Sin esta recuperación, ninguna de sus promesas podrá materializarse y el pacto que se prefigura será coyuntural e inestable. 
La pregunta que despierta esta obligación es si la reconcentración del poder será por las vías democráticas o por la tradición autoritaria. La empresa comenzó con la intención de instalar coordinadores federales en los estados, que fungirán como contrapeso a los gobernadores. Durante el período democrático éstos se habían distinguido tanto por su alto grado de autonomía, como su cinismo frente a la corrupción. El predominio y subordinación de cámaras legislativas, tanto las federales como las locales, es otro paso hacia la reconcentración del poder. En el mismo sentido opera el embate que, con razón o sin ella, ha emprendido contra instituciones ciudadanas (el Instituto Nacional Electoral y los órganos autónomos, por ejemplo) y la desconfianza hacia organismos de la sociedad civil. Todo ello forma parte de una reconcentración del poder, que es necesaria para recuperar la gobernabilidad.

El hecho de que se realice sin contrapesos finca el temor de que esta ruta puede conducir a una versión renacida del viejo autoritarismo priísta. De esta forma parece consolidarse la restitución de uno de los pilares del viejo sistema político: el presidencialismo metaconstitucional. La crisis de los partidos y del desmantelamiento de los contrapesos así lo facilitan. El carácter carismático de la legitimidad abona fuertemente para que el líder recupere sus capacidades arbitrales. Sólo falta un pacto que manifieste el equilibrio entre los actores. Si su consecución se realiza por la vía neo-corporativa, la desembocadura al dilema seguramente será la vía autoritaria. A la restitución de este corporativismo, que en su tiempo fue el otro pilar del sistema político mexicano, se encamina la incorporación de luchadores sociales perseguidos, como la lideresa de la policía comunitaria, Nestora Salgado, o de los mineros, Napoleón Gómez Sada. A ellos se suman los sindicatos de electricistas desmantelados por la política neoliberal (SME). Pero también de antiguos aliados del régimen priísta o panista, como la exlideresa del magisterio, Elba Esther Gordillo; y aun de sus detractores: la CNTE.
Pero también, la gran mayoría de ellos han estado sujetos a juicios por violaciones a la ley. En algunos casos, la justicia los ha exonerado. Pero el dictamen no es tan importante: es el perdón o la defensa que les ha conferido AMLO lo que ha activado una gran legitimidad de su causa entre huestes de simpatizantes entregados. Es en la tolerancia de estas huestes hacia la ilegalidad donde se anida el huevo de la serpiente de la ruta autoritaria.

La reactivación y subordinación de estos actores es un paso importante en este sentido; sin embargo, es insuficiente: la recuperación cabal del corporativismo requiere otorgarles capacidad para aglutinar y movilizar a las masas. Pero, dado el mensaje de las urnas, este atributo no puede ser concedido a estas corporaciones, en virtud del riesgo que entraña el desplazamiento del apoyo popular, ahora concentrado en el presidente, hacia esos esquemas corporativos. Adicionalmente, los compromisos de libertad sindical que ha acarreado el nuevo tratado de comercio con Estados Unidos y Canadá sugieren que cualquier intento de reactivación corporativa se quedará trunco. El mensaje de este hecho es el fortalecimiento de las tendencias caudillistas de presidente, en virtud de que el encuadramiento corporativo de las masas fue una de las piezas claves de la institucionalización del poder en el Ejecutivo y, por esta vía, del abandono de las propensiones caudillistas que encarriló Lázaro Cárdenas (1934-1940): el artífice del viejo sistema político mexicano.

En contra operan las inclinaciones democráticas de ciertos segmentos modernos que, ante la descomposición de la élite política, se inclinaron por López Obrador. Entre ellos se encuentran simpatizantes conspicuos de su movimiento, que en buena parte fungieron inicialmente como sus defensores intelectuales. Una buena parte de ellos han luchado durante años por la democracia y ahora ven en la actuación gubernamental una amenaza permanente de lo que se ha avanzado. De instrumentarse la vertiente autoritaria, seguramente exhibirán un creciente alejamiento del lopezobradorismo, 
tal como lo hicieron muchos combatientes sandinistas con relación a Ortega y su mujer. Sin embargo, la alianza con los líderes como Elba Esther Gordillo o Bartlett, denostados por este grupo durante años por supuestos actos de corrupción y/o entrega al régimen, puede significar la configuración de fuentes alternativas de consenso capaces no solamente de sustituir a esos intelectuales orgánicos, sino de usarlos en su contra. De la misma manera que el priísmo podía contraponer a varios sectores corporativos para garantizar su subordinación.

\section{Conclusiones}

El triunfo de López Obrador en los comicios de julio de 2018 es la crónica de una victoria anunciada. La cuarta transformación parece ser la intención de recuperar las promesas de la democracia al iniciar el milenio: moralidad y control ciudadano del poder. Tales promesas se vieron frustradas por una élite política que secuestró y usó en su provecho las nuevas formas democráticas, hasta que acabó por no representar a nadie, excepto a sí misma. En este sentido, la victoria de AMLO es, ante todo, la recuperación de un espíritu que parecía perdido.

Sólo un líder carismático, con el halo de santidad que le suministra la imagen de no haber pertenecido a esa élite, surge como un personaje capaz de lograr tal empresa. En eso se parece Gandhi; pero también al Che: santidad y beligerancia combinadas. $Y$ por eso, la ciudadanía está dispuesta a perdonarle todo. Así le devuelve al presidente los atributos que, desde Díaz, han tenido los ejecutivos federales: capacidad arbitral. Ésta puede operar sólo en el marco de una institucionalidad blanda, donde la legalidad ocupa un segundo término y nunca puede ser aplicada a actores amparados por la tutela del caudillo.

Así se abona a la solución autoritaria al dilema clásico entre democracia y gobernabilidad. La recuperación de esta última es indispensable. Pero no necesariamente debe instrumentarse mediante una concentración autoritaria del poder: admite la vía demo- crática, que es la que viabiliza el desarrollo pleno y sostenido en el largo plazo. Sin embargo, los astros parecen conjugarse para que éste no sea el derrotero escogido. La intolerancia de las huestes de simpatizantes así lo han determinado; y a ellos se suman personajes que encarnaban el viejo autoritarismo político. De esta forma, se tiende a vigorizar el componente autoritario del Movimiento de Regeneración Nacional, lo que amplía la probabilidad de usarlo contra el grupo de simpatizantes y activistas que han exhibido claras inclinaciones democráticas $y$, sobre todo, antiautoritarias, en caso de un potencial y creciente abandono de ese movimiento. La estabilidad del nuevo pacto dependerá de cuál de los dos componentes del pacto prevalezca: el autoritario en ciernes o el democrático socialmente comprometido. O de otro modo: de si la cuarta trasformación recupera la moralidad y el control ciudadano por medios institucionales o por vías caudillistas.

\section{Fuentes consultadas}

Acemoglu, Daron and Robinson, James A. (2012), Why Nations Fail. The Origins of Power, Prosperity and Poverty, New York, Crown Publisher.

Aguilar, Alonso (1968), Dialéctica de la economía mexicana: del colonialismo al imperialismo. México, Editorial Nuestro Tiempo.

Aguilar, Manuel (1982), El bonapartismo mexicano I. Ascenso y decadencia, México, Juan Pablos.

Cámara de Diputados (2020), "Distribución de diputados por partido", México, Cámara de Diputados, <https://bit.ly/3jjU17q>, 13 de diciembre de 2020.

Cámara de Senadores (2020), "Distribución de Senadores por partido", México, Cámara de Senadores, <https://bit. $|y / 36| \cup d b b>, 13$ de diciembre de 2020.

Córdova, Arnaldo (1973), La política de masas del cardenismo, México, Era. 
Durkheim, Émile (2006), Formas elementales de la vida religiosa, México, Colofón.

Escalante, Fernando (1993), Ciudadanos imaginarios, México, El Colegio de México.

Guerra, Francois-Xavier (1980), México: del antiguo régimen a la Revolución, México, Fondo de Cultura Económica.

INE (2018a), "Programa de Resultados Electorales Preliminares", México, <https:// bit.ly/3oQ9Nbo>, 4 de julio de 2018.

INE (2018b), "Cómputos distritales 2018. Elecciones federales", México, <https:// bit.ly/2Lo9IOY>, 4 de julio de 2018.

Levitsky, Steven and Ziblatt, Daniel (2018), How Democracies Die, New York, Penguin, Kindle Edition.

Millán, Henio (2012), "La democracia secuestrada. Actores sociales y representatividad en México", Perfiles Latinoamericanos, 20 (40), México, Flacso, pp. 165-204.

Moreno-Brid, Juan Carlos and Ros, Jaime (2009), Development and Growth in Mexican Economy. A Historical Perspective. New York, Oxford University Press.

Müller, Jan-Werner (2017), ¿Qué es el populismo?, México, Grano de Sal.

Roeder, Ralph (1970), Hacia el México moderno: Porfirio Díaz, México, Fondo de Cultura Económica.

Urbinati, Nadia (2019), Me the people: how populism transforms democracy, Cambridge, Harvard University Press.

Weber, Max (1922/2002), Economía y Sociedad. Esbozo de sociología comprensiva, Madrid, Fondo de Cultura Económica.

Wikicristiano (2010), "Diccionario Bíblico", wikicriatiano.org, <https://bit.ly/3tofuktDurkheim>, 2 de diciembre de 2020.
Enviado: 11 de diciembre de 2020.

Reenviado: 8 de enero de 2021.

Aceptado: 25 de enero de 2021.

\section{Henio Millán Valenzuela}

Doctor en Ciencias Sociales y Políticas por la Universidad Iberoamericana. Es miembro del Sistema Nacional de Investigadores, nivel III. Ha sido profesor de posgrado en varias instituciones. En 2014 recibió el Premio de Ciencia y Tecnología otorgado por el Consejo Mexiquense de Ciencia y Tecnología. Sus líneas actuales de investigación son: Democracia e instituciones, por un lado, y Pobreza y desarrollo, por el otro. Sus artículos más recientes son, como autor: "Análisis urbano y modelos multinivel. Una introducción", Revista Científica de Estudios Urbano Regionales Hatsö-Hnini, 2 (1), Pachuca, Unión de Investigadores para la Sustentabilidad S.A.S., pp. 3-21 (2020); "Informalidad y heterogeneidad social: eficiencia y cooperación en comunidades y sociedades", Diálogos Latinoamericanos 28 (20), Aarhus, Centro Latinoamericano (LACUA), pp. 5776 (2019), y en coautoría: "Instituciones y educación en México: bienes preferentes, movilidad social y premodernidad", Revista Mexicana de Ciencias Políticas y Sociales, 237 (64), México, pp. 19-42 (2019). Su artículo "Las causas de la crisis financiera" obtuvo el primer lugar en 2011 como el artículo más leído en la historia de la revista Economía, Sociedad y Territorio. Ha publicado 10 libros y más de 50 artículos en revistas especializadas. Entre sus libros más recientes se encuentran: Trampas de la pobreza en México. Historia y economía política (en prensa), En la cuerda floja. Vulnerabilidad hacia la pobreza y fragilidad laboral (2013), Política y desarrollo. Las instituciones en sociedades heterogéneas (2012), Participación y abstencionismo electoral en México (en coautoría con Marta Gloria Morales, Luis Fernández y Marcela Ávila (2011) y Pobreza y Microfinanzas. Una evaluación de impacto (2009). 